\title{
Reliability of MEMS
}

\author{
Ivanka Stanimirović and Zdravko Stanimirović \\ IRITEL A.D. \\ Republic of Serbia
}

\section{Introduction}

Reliability is a key factor for successful commercialization of micro electronic and mechanical systems (MEMS). MEMS devices are becoming essential components of modern engineering systems and their reliability is of particular importance in applications where their failure can be catastrophic and devastating (surgical devices, implantable biosensors, navigation in aerospace, sensors in automotive industry, etc.). However, although MEMS devices are made of minute delicate components realized primarily using physical-chemical processes, the main reason for the lack of success in commercialization of MEMS cannot be attributed to the advance of micro technology but to packaging techniques used in production of MEMS devices. When MEMS packaging is in question, it is of the greatest importance that design and realization of MEMS device must include all levels of reliability issues from the onset of the project. For that reason, this chapter is intended to be a general overview focusing on mechanisms that cause failure of MEMS devices. An insight in reliability of MEMS packaging (types of MEMS packaging, material requirements and package reliability) is given. Also, the reliability of MEMS in view of materials, structural and process reliability and associated failure mechanisms is presented. As the closing subsection the brief summary of the topic will be presented with an emphasis on the importance of the further R\&D work on MEMS reliability testing and development of industrial standard for assembly, packaging and testing.

\section{Reliability in MEMS packaging}

Although the most silicon-based MEMS are produced using the same microfabrication processes developed for integrated circuits (ICs), these two technologies are significantly different and MEMS are not evolved integrated circuits. There are several principal differences between silicon-based MEMS and integrated circuits (Hsu, 2006):

- Silicon-based MEMS are complex 3D structures while integrated circuits are primarily 2D structures.

- Many MEMS devices involve precision movement of solid components and fluids in sealed enclosures, and integrated circuits are stationary encapsulated electric circuits.

- While MEMS perform a great variety of specific functions of biological, chemical, electromechanical and optical nature, integrated circuits transmit electricity for specific electrical functions.

Source: Micro Electronic and Mechanical Systems, Book edited by: Kenichi Takahata, ISBN 978-953-307-027-8, pp. 572, December 2009, INTECH, Croatia, downloaded from SCIYO.COM 
- $\quad$ MEMS as delicate moving or stationary components are interfaced with working media while IC dies are isolated from contacting media.

- MEMS are using silicon and silicon compounds plus variety of other industrial materials, while integrated circuits are limited to single crystal silicon and silicon compounds, ceramic and plastic.

- In MEMS there are many components to be assembled and in integrated circuits there are fewer components to be assembled.

- MEMS packaging technology is far from being developed while IC packaging techniques are relatively well developed.

- For MEMS there are no available industrial standards regarding design, materials selections, fabrication processes and assembly-packaging-testing while integrated circuits have available industrial standards in all these areas.

- Most MEMS are custom built and assembled on batch production lines in contrast to mass production of ICs.

- $\quad$ MEMS have limited sources of commercialization while integrated circuits are fully commercialized.

MEMS packaging is more complex than packaging of integrated circuits because of their complex structures and specific performances. MEMS packaging must provide support and protection to ICs, associate wire bonds and the printed circuit board (PCB) from mechanical or environmentally induced damages and protect elements that require interface with working media which can be environmentally hostile. The fact that many MEMS require non-standard packages is one of the reasons why they have not made their way to the market. There are three basic types of packages used in MEMS technology: ceramic, metal and plastic. Some of the features of these three types of packages are given in table 1.

\subsection{Materials selection for MEMS packaging}

When MEMS devices are in question, materials selection should be done carefully. Similar to IC packaging, most of the MEMS devices are diced from a wafer and mounted on a substrate inside a package and therefore a careful attention must be paid to die attachment materials selection. Die attach material should firmly bond die to the substrate eliminating any possibility of motion. Die movement may cause various problems especially in optoelectronic devices where alignment is important. Fracture toughness is very important for brittle attachment materials because it determines material resistance to fracture. Mismatch of the coefficient of thermal expansion (CTE) between die attach material, silicon and substrate may lead to undesirable stress. Another important factor in attachment materials selection is thermal conductivity because die attachment material conducts heat from the die to the substrate. Moisture adsorption is critical because it causes degradation of die attach bonding properties. In order to minimize stress induced to the die, organic materials (epoxies, silicones, polyamides) are often used as die attach materials. These low cost materials are also convenient because of the ease of rework. However, in unpassivated MEMS devices outgassing of organic material may cause contamination. Organic materials are usually not used for ceramic packages. Temperature needed to produce frit seal after die attachment may lead to the degradation of the adhesive. Inorganic materials are also being used as die attach materials. These materials exhibit excellent fatigue resistance and provide lowest levels of contaminant gasses, but due to the lack of plastic flow may cause mismatch between substrate and die. 


\begin{tabular}{|l|ll|}
\hline Ceramic packaging & $\bullet$ & Commonly used in MEMS packaging \\
& $\bullet$ & Usually consist of a base and a header \\
& $\bullet$ & Die attachment by solder or adhesives \\
& - & Generally electrically insulating \\
& - & Hermetic \\
& & The match between coefficient of linear \\
& & thermal expansion between ceramic and \\
& - & High mechanical strength \\
& $\bullet$ & Resistant to chemicals \\
\hline Metal packaging & $\bullet$ & Robust \\
& $\bullet$ & Easy to assemble \\
& $\bullet$ & Allow prototyping in small volumes with \\
& & short turnaround periods \\
& $\bullet$ & Hermetic when sealed \\
\hline Plastic packaging & $\bullet$ & Cost effective \\
& $\bullet$ & Small weight \\
& $\bullet$ & Allow moist absorption \\
\hline
\end{tabular}

Table 1. Main features of three basic types of packages used in MEMS technology

Substrates for MEMS packaging must meet different electrical, thermal, physical and chemical requirements. One of the most important factors is dielectric constant of the substrate whose high value may cause crosstalk between wires. Another important factor is CTE. In order to minimize the thermal-mechanical stress in the package that may cause cracks or errors (in piezo-resistive sensor elements), CTE values of the substrate, die and die attach material must be matched. Another substrate property that must be taken into consideration is the loss tangent. If the substrate with high loss tangent is used, performances of MEMS devices sensitive to the frequency of applied signals may be reduced significantly. That also may result in low quality factor (Q) which measures performances of MEMS devices. Thermal conductivity of the substrate is important from the aspect of the heat transfer and porosity. Also, porosity and purity of the substrate must be evaluated because of the possibility of moisture penetration through the substrate. Properties of most commonly used substrates for MEMS packaging are given in table 2. It should be pointed out that Low Temperature Cofired Ceramic (LTCC) being the multilayer substrate allows implementation of cavities and allows movement in $\mathrm{Z}$ direction.

\subsection{MEMS package reliability}

When MEMS package reliability is in question, basic issues that should be taken into consideration are issues related to reliability of die attachments, ceramic substrates and released MEMS structures.

Mechanical connection between the substrate and MEMS structure is provided by die attach materials. CTE mismatch between used materials induces stress on the MEMS structure that may lead to formation of cracks on silicon MEMS structure. Cracks can appear at the centre or at the corners of the die usually when hard adhesives are used as die attach materials. In that case, CTE mismatch stress is transferred to the die causing cracks. Die attach can also crack if soft adhesives are used because it acts as a strain buffer at the die-substrate interface. 


\begin{tabular}{|l|c|c|c|c|}
\hline $\begin{array}{c}\text { Single Layer } \\
\text { Substrates }\end{array}$ & $\begin{array}{c}\text { Tensile } \\
\text { Strength } \\
(\mathrm{MPa})\end{array}$ & $\begin{array}{c}\text { Elastic } \\
\text { Modulus } \\
(\mathrm{GPa})\end{array}$ & $\begin{array}{c}\text { Flexural } \\
\text { Strength } \\
(\mathrm{MPa})\end{array}$ & $\begin{array}{c}\text { Dielectric } \\
\text { Strength } \\
(\mathrm{kV} / \mathrm{mm})\end{array}$ \\
\hline $\mathrm{BeO}$ & 230 & 345 & 250 & 0.78 \\
\hline $\mathrm{Si}$ & - & $310-343$ & 360 & 0.55 \\
\hline $\mathrm{AlN}$ & - & 190 & 580 & - \\
\hline $\mathrm{Al}_{2} \mathrm{O}_{3}(96 \%)$ & 127.4 & 310.3 & 317 & 0.33 \\
\hline $\mathrm{Al}_{2} \mathrm{O}_{3}(96 \%)$ & 206.9 & 345 & 345 & 0.33 \\
\hline Steatite & $55.2-69$ & $90-103$ & 110 & $7.9-15.7$ \\
\hline Fosforite & $55.2-69$ & $90-103$ & 124 & $7.9-11.8$ \\
\hline Quartz & 48.3 & 71.7 & - & - \\
\hline
\end{tabular}

\begin{tabular}{|l|c|c|c|}
\hline $\begin{array}{c}\text { Single Layer } \\
\text { Substrates }\end{array}$ & $\begin{array}{c}\text { Dielectric } \\
\text { Constant } \\
@ 1 \mathrm{MHz}\end{array}$ & $\begin{array}{c}\text { Thermal } \\
\text { Conductivity } \\
\left(\mathrm{W} / \mathrm{m}^{\circ} \mathrm{C}\right)\end{array}$ & $\begin{array}{c}\mathrm{CTE} \\
\left(\mathrm{ppm} /{ }^{\circ} \mathrm{C}\right)\end{array}$ \\
\hline $\mathrm{BeO}$ & $6.7-8.9$ & $150-300$ & $6.3-7.5$ \\
\hline $\mathrm{Si}$ & $8.5-10$ & $82-320$ & $4.3-4.7$ \\
\hline $\mathrm{AlN}$ & 11.9 & $125-148$ & 2.33 \\
\hline $\mathrm{Al}_{2} \mathrm{O}_{3}(96 \%)$ & $4.5-10$ & $15-33$ & $4.3-7.4$ \\
\hline $\mathrm{Al}_{2} \mathrm{O}_{3}(99 \%)$ & $4.5-10$ & $15-33$ & $4.3-7.4$ \\
\hline Steatite & $5.5-7.5$ & $2.1-2.5$ & $8.6-10.5$ \\
\hline Fosforite & 6.2 & $2.1-4.2$ & 11 \\
\hline Quartz & 4.6 & 43 & $1.0-5.5$ \\
\hline Multilayer Substrate & $6-9$ & $2-4$ & $5-7$ \\
\hline LTCC &
\end{tabular}

Table 2. Properties of commonly used substrates for MEMS packaging (Pecht, 1998)

When organic die attach materials are being used, outgassing becomes an issue. In that case vacuum packaging is recommended. It protects MEMS devices from damage and contamination. Besides outgassing, if the organic die attach material is being used, moist absorption may cause failure. In hermetically sealed packages moisture trapping may occur causing delamination.

When ceramic substrate reliability is in question, CTE mismatch between substrate and silicon die may induce stress on the die causing cracking or bending. This can be avoided by careful evaluation of material properties. Matching CTE values of the substrate and the die lead to elimination of this problem.

Another reliability issue when MEMS package reliability is in question is packaging of released MEMS structures. Since they are susceptible to contamination, excessive handling, mechanical shock and stiction caused by the presence of moisture, the wafer level vacuum packaging is recommended.

\section{Reliability of MEMS}

Variety of applications may lead to misconception that amount of different structural parts of MEMS devices is large. However, there are a number of basic parts that are being used: cantilever beams, membranes, hinges, etc. The most common generic MEMS elements are listed in table 3. 
- $\quad$ Structural beams

- rigid

- flexible

- $\quad$ one side clamped

- $\quad$ two sides clamped

- Structural thin membranes

- rigid

- flexible

- with holes

- Flat layers (usually adhered to substrate)

- conductive

- insulating

- Hinges

- substrate hinge

- scissors hinge

- Cavities

- sealed

- open

- Gears

- teeth

- hubs

- $\quad$ Tunnelling tips

- Reflective layers

Table 3. Generic MEMS elements (Merlijn van Spengen, 2003)

MEMS devices are usually batch fabricated using silicon wafers as the material and etching techniques to build components. Fabrication process is more complex than fabrication process of ICs because of mechanical parts and electromechanical parts that are being integrated with electronic parts on the same substrate. MEMS have more complex shapes, have moving parts and need more material strength. Mechanical parts need special attention throughout the production cycle: from material deposition to material removal. These parts may have complex shapes, may require material with special strength and may have moving parts. Therefore, deposited film must be thick enough to form the mechanical layer. Moving parts are released after etching away the $\mathrm{SiO}_{2}$ layer. Common processing techniques include bulk micromachining, wafer-to wafer bonding, surface micromachining and high-aspect ratio micromachining. Many MEMS failure modes are introduced in the fabrication process. Also, many failure modes in operation are related to fabrication process. MEMS common failure modes are fracture, creep, stiction, electromigration, wear, degradation of dielectrics, delamination, contamination, pitting of contacting surfaces, electrostatic discharge (ESD), etc.

One of the most important failure modes is stiction. Due to small sizes of MEMS structures surface forces dominate all others. The most important surface forces in MEMS are electrostatic force, capillary force and molecular van der Waals force (Tadigadapa, 2001). They cause stiction between microscopic structures when their surfaces come into contact. It can affect even elements that are not powered. Illustration of this failure mode is given in figure 1 . 


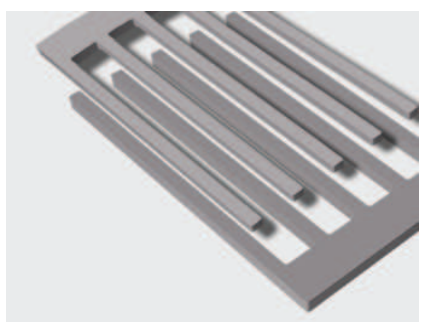

Fig. 1. Illustration of stiction failure mode

Creep is important issue for reliability of metal MEMS. High stresses and stress gradients introduce possibility of time-dependent mass transfer through glide and diffusion mechanisms. The creep is much more severe in MEMS structures than expected from macroscopically known behaviour. Macroscopically, creep is negligible. MEMS manufacturers should pay special attention when using metal as a structural material in MEMS where room temperature creep exists.

Most metals and alloys are degraded by material fatigue when subjected to a large repetitive mechanical stress. Cyclic loading of MEMS couples with other failure mechanisms associated with static loading, creep and environmental effects. Any process that results in an irreversible repositioning of atoms within a material can contribute to fatigue. Brittle materials like ceramics and silicon do not have a significant cyclic fatigue effect. Poly and possibly mono-crystalline silicon seem to suffer from a stress corrosion cracking mechanism (Muhlstein, 1997). In a not completely water free environment, small cracks propagate under tensile stress, due to hydrolysis of the native oxide layer (fig.2).
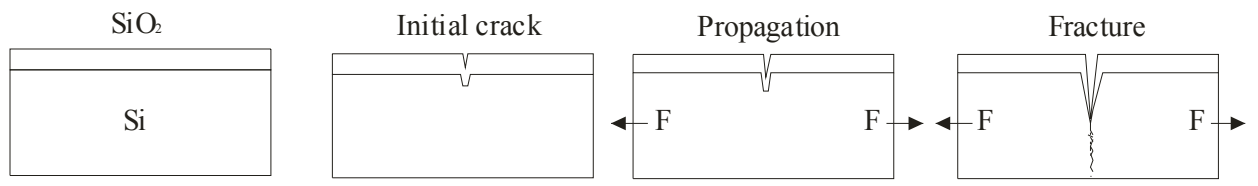

Fig. 2. Stress corrosion cracking failure mechanism

Friction and wear are of interest when sliding/rotating MEMS are in question. The wear mechanism in silicon is adhesive wear (Merlijn van Spengen, 2003). Rough contacting surfaces adhere to each other at their highest points. These points are broken and stay attached to other surfaces. Material is then transferred between surfaces and when asperities grow to a certain size they break off leaving worn surface and causing the accumulation of debris. Illustration of adhesive wear is shown in figure 3.
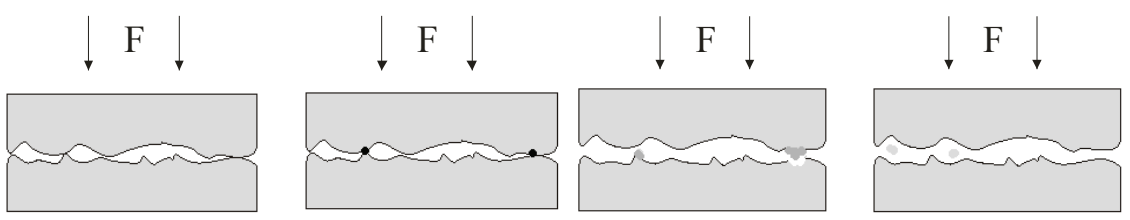

Fig. 3. Illustration of adhesive wear

Dielectric charging is an important issue for reliability of MEMS that contain dielectric layers. Parasitic charge accumulating in MEMS may alter actuation voltages and affect mechanical 
behavior of the device. Also, a common problem is charging due to high field strengths required for actuation of electrostatically actuated MEMS.

Delamination is associated with multilayer films. High stress can be introduced by processing, thermal mismatch or epitaxial mismatch. The adhesion between layers depends strongly on their chemical and mechanical compatibility.

Electrostatic clamping of gears may prevent gears from moving due to presence of electrical charges at certain energy levels.

Particles have a damaging effect on devices where small gaps exist between bearing surfaces or elements with large potential difference. Particulate contamination is important when contaminating particles are internally generated or present in spite of a clean room environment.

Environmental effects may be important for design of variety of MEMS applications. Environmental Attack is of interest in case of valves, sensors and pumps where contacting fluids may be corrosive resulting in crack growth.

MEMS failure mechanisms are numerous and list of possible failure modes does not end here. Root causes of MEMS failure modes are different from the common causes on macroscopic level. Some of them are capillary forces, operational methods, mechanical and electrical instabilities. MEMS failure analysis techniques are similar to techniques that are being applied in failure analysis of ICs: optical microscopy, scanning laser microscopy, scanning electron microscopy, focused ion beam, atomic force microscopy, light emission, acoustic microscopy, acoustic emission, laser cutting, lift-off technique, etc. Failure models for MEMS are scarce because a failure model should be able to describe physic of failure and allow failure prediction. It is obvious that current knowledge of MEMS reliability is insufficient in comparison with the amount of MEMS devices that are already available.

\section{Conclusion}

An insight in reliability of MEMS packaging and the reliability of MEMS has been presented in this chapter. Since there is a common misconception that silicon MEMS devices and ICs are similar because they use the same microfabrication techniques, principal differences between silicon-based MEMS and ICs have been outlined. Materials selection for MEMS packaging has been considered as well as MEMS package reliability. As far as MEMS generic elements are concerned, a number of common failure modes have been presented. Reliability of MEMS devices requires better understanding of mechanisms that cause failure in MEMS devices. Production of reliable MEMS device requires sophisticated design considerations and better control of microfabrication processes that are used in production and packaging of a MEMS device. Reliable MEMS package should isolate non-sensing areas from sensing ones what is of extreme importance in harsh, corrosive or mechanically demanding environments. Also, it must not prevent mechanical action of moving parts of the structure or disable transfer of fluids from one region to another. Coupling of energy, motion or momentum from one region to another should be allowed. Finally, reliable MEMS package should prevent transfer of heat, mechanical strain, outgassing, pressure, moisture, etc. Reliability of MEMS generic elements is also of utmost importance. Knowledge of physics of degradation and failure mechanisms in the microdomain is still very limited. Another important issue is the need for credible testing techniques to be used during fabrication, assembly and packaging as well as during operation of the device. Device with self-testing capability will insure the reliability of the device during service. 
It should be pointed out that little research and development efforts have been made in the area of testing. MEMS reliability studies lack dedicated equipment and the development of new and the upgrading of existing equipment is highly desirable. Also, highly diversified functions and materials involved make industrial standard for MEMS packaging almost impossible task. Projected timeline for standardization of MEMS technology is at least five years away (Hsu, 2006). Till then MEMS devices will be custom made according to customer's requirements and the lack of information flow as well as the reluctance in sharing experience and knowledge will keep MEMS still far away from the full commercialization.

\section{Acknowledgement}

Authors are grateful for the partial support of the Ministry of Science and Technological Development of Republic of Serbia (contract TP- 11014).

\section{References}

Hsu, T-R. (2006). Reliability in MEMS packaging, Proceedings of 44th International Reliability Physics Symposium, ISBN: 0-7803-9498-4, San Jose, CA, March 26-30, 2006, IEEE International

Merlijn van Spengen, W. (2003). MEMS reliability from a failure mechanisms perspective. Microelectronics Reliability, 43, 7, (2003) 1049-1060, ISSN: 0026-2714

Muhlstein, C. \& Brown, S. (1997). Reliability and Fatigue testing of MEMS, In: NSF/AFOSR/ASME Workshop, Tribology Issues and Opportunities in MEMS, Bhushan, B. pp. 519- 528, Springer, ISBN: 0792350243

Pecht, M.G.; Agarwal, R.; McCluskey, P.; Dishongh,T.; Javadpour, S. \& Mahajan, R.(1998). Electronic Packaging Materials and Their Properties, CRC Press, ISBN: 9780849396250, USA

Tadigadapa, S. \& Najafi, N. (2001). Reliability of Microelectromechanical Systems (MEMS), Proceedings of Reliability, Testing, and Characterisation of MEMS/MOEMS Conference, pp. 197-205, ISBN: 0-8194-4286-0, San Francisco, CA, October 22-24 2001, SPIE, Bellingham, USA 


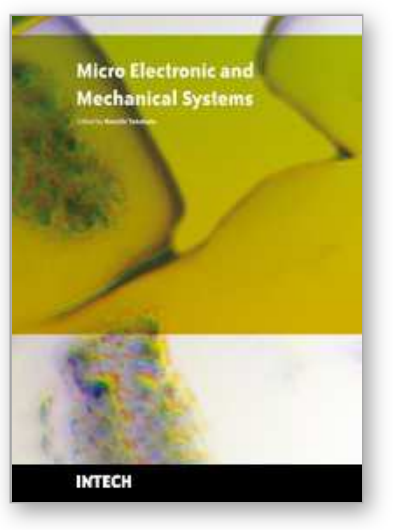

\author{
Micro Electronic and Mechanical Systems \\ Edited by Kenichi Takahata
}

ISBN 978-953-307-027-8

Hard cover, 386 pages

Publisher InTech

Published online 01, December, 2009

Published in print edition December, 2009

This book discusses key aspects of MEMS technology areas, organized in twenty-seven chapters that present the latest research developments in micro electronic and mechanical systems. The book addresses a wide range of fundamental and practical issues related to MEMS, advanced metal-oxide-semiconductor (MOS) and complementary MOS (CMOS) devices, SoC technology, integrated circuit testing and verification, and other important topics in the field. Several chapters cover state-of-the-art microfabrication techniques and materials as enabling technologies for the microsystems. Reliability issues concerning both electronic and mechanical aspects of these devices and systems are also addressed in various chapters.

\title{
How to reference
}

In order to correctly reference this scholarly work, feel free to copy and paste the following:

Ivanka Stanimirović and Zdravko Stanimirović (2009). Reliability of MEMS, Micro Electronic and Mechanical Systems, Kenichi Takahata (Ed.), ISBN: 978-953-307-027-8, InTech, Available from:

http://www.intechopen.com/books/micro-electronic-and-mechanical-systems/reliability-of-mems

\section{INTECH}

open science | open minds

\section{InTech Europe}

University Campus STeP Ri

Slavka Krautzeka 83/A

51000 Rijeka, Croatia

Phone: +385 (51) 770447

Fax: +385 (51) 686166

www.intechopen.com

\section{InTech China}

Unit 405, Office Block, Hotel Equatorial Shanghai

No.65, Yan An Road (West), Shanghai, 200040, China

中国上海市延安西路65号上海国际贵都大饭店办公楼 405 单元

Phone: +86-21-62489820

Fax: +86-21-62489821 
(C) 2009 The Author(s). Licensee IntechOpen. This chapter is distributed under the terms of the Creative Commons Attribution-NonCommercialShareAlike-3.0 License, which permits use, distribution and reproduction for non-commercial purposes, provided the original is properly cited and derivative works building on this content are distributed under the same license. 